\title{
Synchronous Bilateral Ureteric Metastases as the Presenting Manifestation of Gastric Cancer
}

\author{
Swei H Tsung
}

\section{ABSTRACT}

A 55-year-old man sought medical attention because of the right flank pain. He was anemic with impaired renal function and was admitted to the hospital. Computer tomography demonstrated bilateral hydronephrosis due to ureteral obstruction. Biopsy of both ureters and immunohistochemical staining led to the final diagnosis of gastric carcinoma metastasizing to both ureters. This article presented a case in which metastases of the ureters were the first and sole presentation of gastric cancer.

Keywords: Gastric cancer, Ureteral metastases, Hydronephrosis, Immunohistochemical stainings, Chemotherapy.

Published Online: October 14, 2020

ISSN: 2593-8339

DOI: $10.24018 /$ ejmed.2020.2.5.505

\section{Swei H Tsung*}

M.D., Department of Pathology, St Mary's Hospital, Loudong, Yilan, Taiwan

(e-mail: tsung.sweihsiung@gmail.com)

*Corresponding Author

\section{INTRODUCTION}

Metastasis of gastric carcinoma to the ureter is very rare. In most published cases, the diagnosis was only made at advanced stage or at autopsies. In a systematic review [1], $\mathrm{Hu}$ et al. found 265 patients with cancer metastasizing to the ureters. Prostate, bladder, breast, gastrointestinal tract cancer and malignant lymphoma were the predominant primary tumor. This report presented a patient with gastric cancer who developed hydronephrosis caused by ureteral metastasis, without any symptoms of the primary lesions.

\section{CASE REPORT}

A 55-year-old man who sought medical attention because of the right flank pain. His laboratory test results were abnormal; serum levels of creatinine and BUN were 5.2 $\mathrm{mg} / \mathrm{dl}$ and $58.6 \mathrm{mg} / \mathrm{dl}$ respectively. His estimated glomerular filtration rate of $12.3 \mathrm{~mL} / \mathrm{min} / 1.73 \mathrm{~m}^{2}$. He was anemic with hemoglobin level of $8.6 \mathrm{~g} / \mathrm{dl}$. He was admitted to our hospital under the urologist's care. Computer tomography revealed hydronephrosis of both kidneys (Fig. 1, A). No tumor was found in any other organs. Cystoscopic examination showed a normal mucosa. Both sides retrograde pyelography (RP) were not successfully done because of obstruction found at $2 \mathrm{~cm}$ above the ureterovesical junction. However, biopsies were taken from both ureters with an identical histopathology report. The lining epithelium was intact. The muscle layer was invaded by nests of malignant cells with glandular arrangement (Fig. 1, B). The diagnosis of metastatic adenocarcinoma was rendered.

Immunohistochemical stainings were performed to search for the possible primary site. CK:20、TTF1 - GATA-
3. and PAS were negative; CK7 was positive. The pathologist suggested that the stomach might be the primary site (Fig. 1, C). The gastroenterologist was consulted. The patient underwent the gastroscopic examination, and a gastric tumor was found (Fig. 1, D). Histopathology examination of the biopsy specimen revealed adenocarcinoma (Fig. 1, E), matching that was seen in the ureter biopsy specimen. Thus, it was concluded that both ureter tumors were metastases from the gastric cancer. The patient failed to have double-J stents inserted. Therefore, he had bilateral percutaneous nephrostomy done before he was referred to the oncology department for chemotherapy.

\section{DISCUSSION}

The first case of gastric cancer metastasizing to the ureter was first reported by Schlangintweit in 1911 [2]. Since then, reports describing ureteral metastasis from the stomach have been occasionally published [3]-[5]. In the review paper by $\mathrm{Hu}$ et al., they described 12 stomach cancer patients who developed ureter metastases [1]. The true metastasis has to meet the criterion published by Tresman and Ehrlich as follows [6], "the demonstration of malignant cells in a portion of the ureteral wall together with the absence of any neoplasm in adjacent tissues". The present case showed no tumorous lesions around the ureters or in the retroperitoneal space indicating that the disease was true ureteral metastasis from the stomach according to the criterion of Presman and Ehrlich. The ureteral metastasis could occur years after subtotal gastrectomy [3], [5]. The case reported by Shimoyam et al. [4] was similar to our case. Their patient initially complained of the right flank pain caused by the right ureteral obstruction. She was admitted to the hospital, where she underwent a right nephrouretrectomy, with 
suspicion of primary ureteral neoplasm. The resected ureter showed metastatic adenocarcinoma, and subsequent extensive search for the primary lesion revealed asymptomatic gastric cancer. The present case had the advantage of immunohistochemical studies which suggested the stomach as the possible primary site, and was quickly confirmed, saving the unnecessary surgery.

The present patient's disease indicated a very advanced stage of gastric cancer, even other organs appeared to be

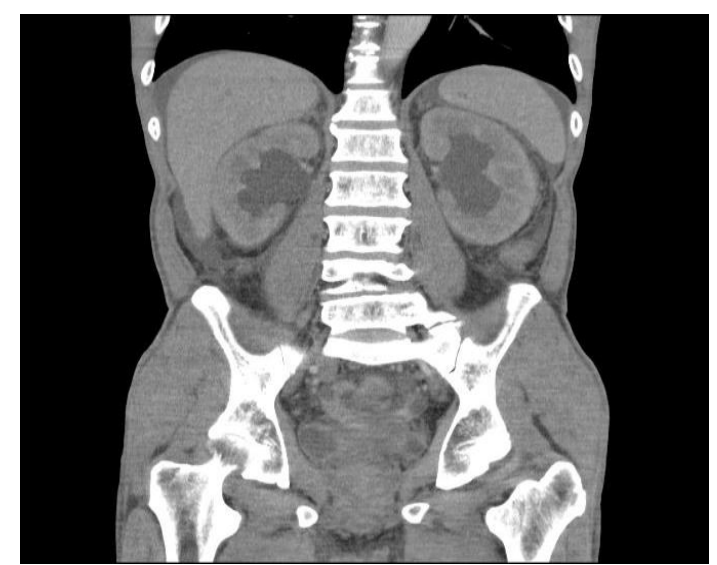

a)

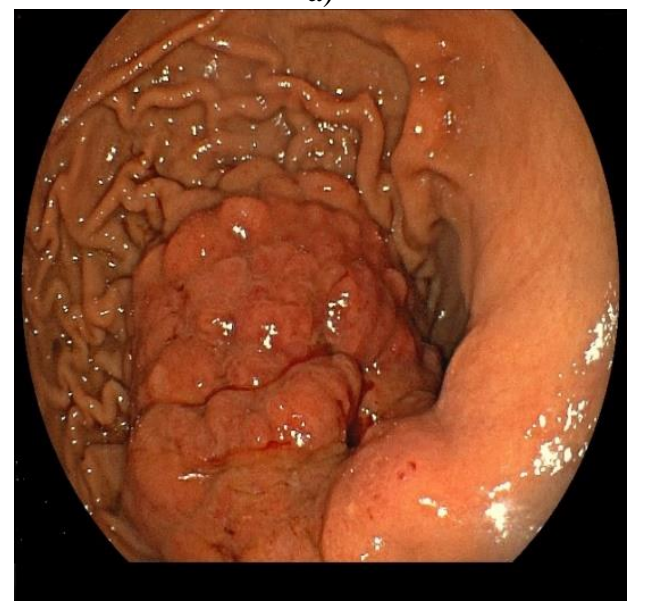

c) free of the disease. In the literature, there has been no report describing any effective therapy for this condition. We encountered a patient with AFP-GC with extensive liver metastasis. His Her2/neu was strongly positive, he received Herceptin in combination with chemotherapy using oxaliplatin plus capecitabine and has been disease free for four years [7]. The present patient's biopsy specimen was negative for Her2/neu therefore, he was not a candidate for target therapy [8].

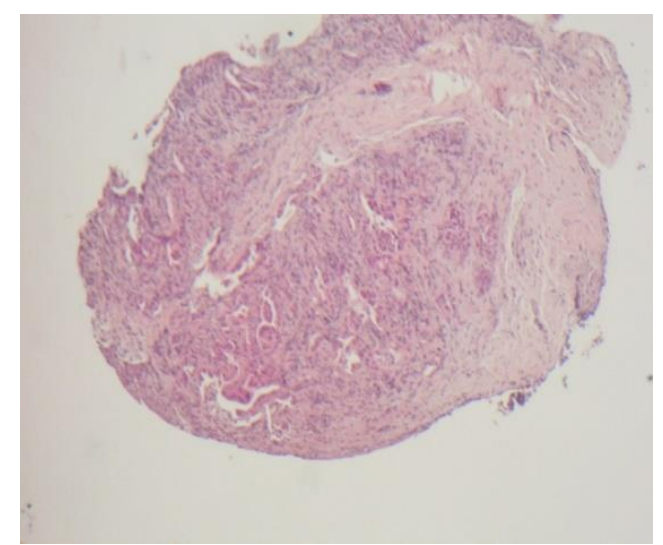

b)

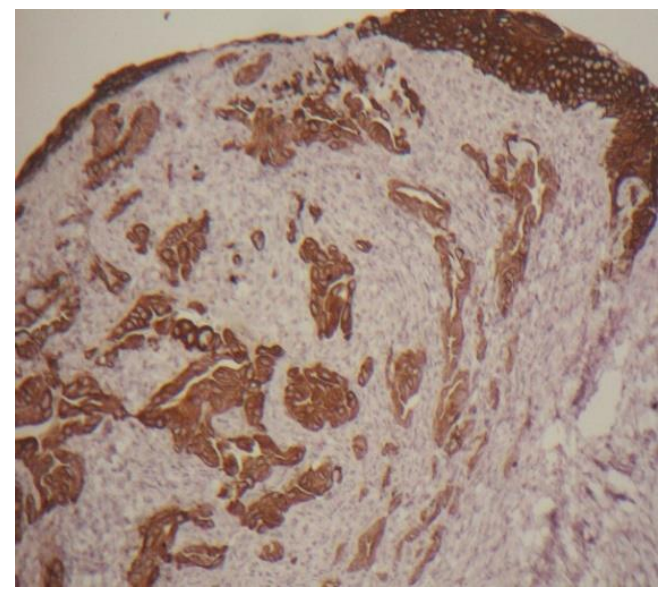

d)

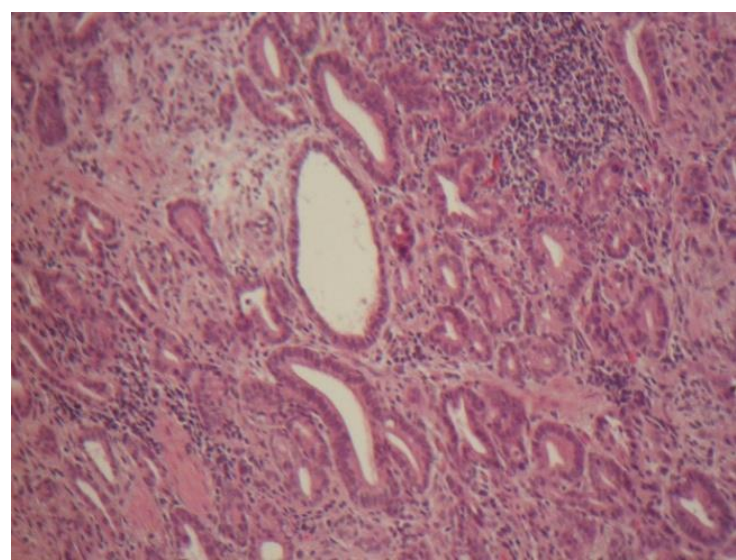

e)

Fig. 1. A. Computer tomography revealed hydronephrosis of both kidneys.

B. Histological examination of both ureters revealed malignant cells with glandular arrangement invading the muscular layer. The mucosal lining was intact. (H\&E stain, $x 400)$.

C. The neoplastic cells were strongly positive for CK7 (Immunohistochemical staining, $\mathrm{x} 400$ ).

D. Gastroscopic examination showed a tumor in the stomach.

E. The biopsy specimen of the stomach displayed adenocarcinoma.(H\&E stain, $\mathrm{x} 400$ ). 


\section{CONCLUSION}

The treatment of cancer metastatic to the ureter is difficult, and outcomes are poor. Early recognition of the metastases and prompt institution of appropriate therapy may prolong survival [9]. The prognosis is generally poor and the survival for more than 2 years has not been reported [4]. The possibility of ureter metastases should not be neglected at any time as it may occur 20 years after diagnosis of a primary cancer [10]

\section{REFERENCES}

[1] Hu J, Deng J, Guo J, Fu B. Ureteral involvement by metastatic malignant disease. Clinical and Experimental Metastasis. 2019, Springer Nature BV.

[2] Schlagintweit F, Metastatische karzinose der ureteren mit anuria bei gleichzeitiger nephritis. Z Urologie 1911; 5: 665-71.

[3] Bisof V, Juretic A, Pasini J, Coric M, Grgic M Gamulin M,Rakustic Z, Krajina Z, Basic-Koretic M, Misiri A, Stern-Padovan R. Ureteral metastasisi as the first and sole manifestation of gastric cancer dissemination. Radiol Oncol 2010; 44: 262-264.

[4] Shimoyama Y, Ohashi M, Hashiguchi N, Ishihara M, Sakata M, Tamura Am Asato Y, Sattoh K, Mukai M. Gastric cancer recognized by metastasis to ureter. Gastric Cancer 2000; 3: 102-105.

[5] George K, Al Hooti QM, Al Busaidy SS, Joseph M, Kamona A. Synchronous bilateral ureteric metastasis from gastric cancer. Urology Annals 2015; 7: 408-409.

[6] Presman D, Ehrlich L. Metastatic tumor of the ureter. J Urol 1948; 59:312-325.

[7] Kuo CY, Tsai CI, Tsung, SH. Complete Clinical Response to a Patient with Advanced Alpha-fetoprotein Producing Gastric Cancer Treated with Chemotherapy and Trastuzumab. Gastrointestinal Cancer: Research and therapy 2017; 2:1-3.

[8] Aizawa M, Nagatsuma AK, Kitada K, Kuwata T, Fujii S, Kinoshita $\mathrm{T}$, Ochiai A. Evaluation of HER2-based biology in 1006 cases of gastric cancer in Japanese population. Gastric Cancer 2014; 1:34-42

[9] .Babaian RJ, Johonson DE, Ayala AG, Sie ET. Secondary tumors of ureter. Urology 1979; 14:341-341.

[10] Feun LG, Drelichman Am Singhakowinta A, Vaitkevcius VK. Ureteral obstruction secondary to metastatic breast carcinoma. Cancer 1979; 44:1164-1171. 